\title{
OPTIMIZATION AND CONTROL WITH APPLICATIONS
}




\section{Applied Optimization}

VOLUME 96

Series Editors:

Panos M. Pardalos

University of Florida, U.S.A.

Donald W. Hearn

University of Florida, U.S.A. 


\section{OPTIMIZATION AND CONTROL WITH APPLICATIONS}

Edited by

LIQUN QI

The Hong Kong Polytechnic University, Hong Kong

KOKLAY TEO

The Hong Kong Polytechnic University, Hong Kong

XIAOQI YANG

The Hong Kong Polytechnic University, Hong Kong

照 Springer 
Library of Congress Cataloging-in-Publication Data

A C.I.P. record for this book is available from the Library of Congress.
ISBN 0-387-24254-6
e-ISBN 0-387-24255.4
Printed on acid-free paper.

\section{(ㄷ) 2005 Springer Science+Business Media, Inc.}

All rights reserved. This work may not be translated or copied in whole or in part without the written permission of the publisher (Springer Science+Business Media, Inc., 233 Spring Street, New York, NY 10013, USA), except for brief excerpts in connection with reviews or scholarly analysis. Use in connection with any form of information storage and retrieval, electronic adaptation, computer software, or by similar or dissimilar methodology now know or hereafter developed is forbidden.

The use in this publication of trade names, trademarks, service marks and similar terms, even if the are not identified as such, is not to be taken as an expression of opinion as to whether or not they are subject to proprietary rights.

Printed in the United States of America.

98776554321

SPIN 11367154

springeronline.com 


\section{Contents}

Preface

Part 1 DUALITY AND OPTIMALITY CONDITIONS

1 ON MINIMIZATION OF MAX-MIN FUNCTIONS

A.M. Bagirou and A.M. Rubinov

1 Introduction 4

2 Special Classes of Max-min Objective Functions 6

3 Discrete Max-min Functions 25

4 Optimization Problems with Max-min Constraints 27

5 Minimization of Continuous Maximum Functions $\quad 29$

6 Concluding Remarks $\quad 30$

$\begin{array}{ll}\text { References } & 31\end{array}$

2 A COMPARISON OF TWO APPROACHES TO SECOND-ORDER SUBDIFFERENTIABILITY CONCEPTS WITH APPLICATION TO OPTIMALITY CONDITIONS

A. Eberhard and C. E. M. Pearee

1 Introduction 36

2 Preliminaries 41

3 Characterization of Supported Operators 46

$4 \quad$ Generalized Convexity and Proximal Subderivatives 53

5 Generalized Convexity and Subjets 60

6 Subjet, Contingent Cone Inclusions 66

7 Some Consequences for Optimality Conditions 76

8 Appendix $\quad 91$

References $\quad 95$

3

DUALITY AND EXACT PENALIZATION VIA A GENERALIZED AUGMENTED LAGRANGIAN FUNCTION

$X . X$. Huang and X.Q. Yang

1 Introduction 
$2 \quad$ Generalized Augmented Lagrangian 102

3 Strong Duality 106

4 Exact Penalty Representation $\quad 108$

5 Conclusions 113

$\begin{array}{ll}\text { References } & 113\end{array}$

4

DUALITY FOR SEMI-DEFINITE AND SEMI-INFINITE PROGRAMMING WITH 115 EQUALITY CONSTRAINTS

S.J. Li, X.Q. Yang and K.L. Teo

1 Introduction and Preliminaries $\quad 116$

2 Uniform Duality for Homogeneous (SDSIP) 118

3 Uniform Duality for Nonhomogeneous (SDSIP) 120

$\begin{array}{ll}\text { References } & 125\end{array}$

5

THE USE OF NONSMOOTH ANALYSIS AND OF DUALITY METHODS 127

FOR THE STUDY OF HAMILTON-JACOBI EQUATIONS

Jean-Paul Penot

1 Introduction 128

2 The Interest of Considering Extended Real-valued Functions 128

3 Solutions in the sense of Unilateral Analysis 131

4 Validity of Some Explicit Formulae 133

5 Uniqueness and Comparison Results 135

$\begin{array}{ll}\text { References } & 137\end{array}$

6

SOME CLASSES OF ABSTRACT CONVEX FUNCTIONS 141

$\begin{array}{ccc}\text { A.M. Rubinov and A.P. Shveidel } & \\ 1 & \text { Introduction } & 142\end{array}$

2 Sets $\mathcal{P}_{k} \quad 145$

3 Supremal Generators of the Sets $\mathcal{P}_{k} \quad 146$

$4 L^{k}$-Subdifferentials $\quad 151$

$\begin{array}{ll}\text { References } & 153\end{array}$

Part II OPTIMIZATION ALGORITHMS

7

AN IMPLEMENTATION OF TRAINING DUAL-nu SUPPORT VECTOR MACHINES 157

Hong-Gunn Chew, Cheng-Chew Lim and Robert E. Bogner.

1 Introduction 158

2 Dual- $\nu$ Support Vector Machines 158

3 Optimisation Method 160

4 Initialisation Technique 168

5 Implementation Issues 172

6 Performance Results 175

7 Conclusions 178 
8

AN ANALYSIS OF THE BARZILAI AND BORWEIN GRADIENT METHOD FOR UNSYMMETRIC LINEAR EQUATIONS

Yu-Hong Dai, Li-Zhi Liao and Duan Li

1 Introduction

2 Case of Identical Eigenvalues

3 Properties of the Recurrence Relation (2.8)

4 Case of Different Eigenvalues

5 Properties of the Recurrence Relation (4.11)

6 Concluding Remarks

9

AN EXCHANGE ALGORITHM FOR MINIMIZING SUM-MIN FUNCTIONS

Alexei $V$. Demyanov

1 Introduction

2 Statement of the Problem

3 Equivalence of the Two Problems

4 Minimality Conditions

5 An Exchange Algorithm

6 An $\varepsilon$-Exchange Algorithm

7 An Application to One Clustering Problem

8 Conclusions

References

10

ON THE BARZILAI-BORWEIN METHOD

Roger Fletcher

1 Introduction

2 The BB Method for Quadratic Functions

3 The BB Method for Non-quadratic Functions

4 Discussion

5 Optimization with Box Constraints

References

11

THE MODIFIED SUBGRAIDENT METHOD FOR EQUALITY CONSTRAINED NONCONVEX OPTIMIZATION PROBLEMS

Rafail N. Gasimov and Nergiz A. Ismayilova

1 Introduction

2 Duality

3 Solving the Dual Problem 
12

INEXACT RESTORATION METHODS FOR NONLINEAR PROGRAMMING: ADVANCES AND PERSPECTIVES

José Mario Martínez and Elvio A. Pilotta

1 Introduction

2 Main Inexact Restoration Ideas

3 Definition of an IR Algorithm

4 AGP Optimality Condition

5 Order-Value Optimization

6 Bilevel Programming 283

7 Homotopy Methods 286

8 Conclusions 287

$\begin{array}{lr}\text { References } & 289\end{array}$

13

QUANTUM ALGORITHM FOR CONTINUOUS GLOBAL OPTIMIZATION

V. Protopopescu and J. Barhen

$1 \quad$ Global Optimization Problem 294

2 Grover's Quantum Algorithm 296

3 Solution of the Continuous Global Optimization Problem 299

4 Practical Implementation Considerations 300

$\begin{array}{ll}\text { References } & 302\end{array}$

14

SQP VERSUS SCP METHODS FOR NONLINEAR PROGRAMMING 305

Klaus Schittkowski and Christian Zillober

1 Introduction 306

2 A General Framework 308

3 SQP Methods 311

4 SCP Methods 314

5 Comparative Performance Evaluation 318

6 Some Academic and Commercial Applications 322

7 Conclusions 324

$\begin{array}{ll}\text { References } & 325\end{array}$

15

AN APPROXIMATION APPROACH FOR LINEAR PROGRAMMING IN MEASURE SPACE

C.F. Wen and S.Y. Wu

1 Introduction

2 Solvability of LPM 335

3 An Approximation Scheme For LPM 336

$4 \quad$ An Algorithm For (DELPM) ${ }^{k} \quad 344$

References 
Part III OPTIMAL CONTROL

16

OPTIMAL CONTROL OF NONLINEAR SYSTEMS

S.P. Banks and T. Cimen

1 Introduction

2 The Approximating Systems

3 Example

4 Results

363

5 Conclusions

References

17

PROXIMAL-LIKE METHODS FOR CONVEX MINIMIZATION PROBLEMS

Christian Kanzow

1 Introduction

2 Proximal-like Methods

3 Numerical Results for Some Optimal Control Problems

381

4 Final Remarks

References

18

ANALYSIS OF TWO DIMENSIONAL NONCONVEX VARIATIONAL PROBLEMS

René Meziat

1 Introduction

2 The Method of Moments

3 Convex Envelopes

396

4 Problem Analysis

399

5 Discrete and Finite Model

400

6 Examples

402

7 Concluding Remarks

References

19

STABILITY OF EQUILIBRIUM POINTS OF PROJECTED DYNAMICAL SYSTEMS

Mauro Passacantando

1 Introduction

2 Variational and Dynamical Models

3 Stability Analysis

4 Special Cases

References

20

ON A QUASI-CONSISTENT APPROXIMATIONS APPROACH TO OPTIMIZATION PROBLEMS WITH TWO NUMERICAL PRECISION PARAMETERS Olivier Pironneau and Elijah Polak

1 Introduction

2 An Algorithm Model 
3 A Distributed Problem with Control in the Coefficients 436

4 Conclusions 440

5 Appendix: Consistent Approximations 442

$\begin{array}{ll}\text { References } & 444\end{array}$

21

NUMERICAL SOLUTIONS OF OPTIMAL SWITCHING CONTROL PROBLEMS

T. Ruby and V. Rehbock

1 Introduction

2 Problem Formulation

3 Solution Strategy

4 Numerical Examples and Discussion

5 Conclusions

References

22

A SOLUTION TO HAMILTON-JACOBI EQUATION BY NEURAL NETWORKS

AND OPTIMAL STATE FEEDBACK CONTROL

Kiyotaka Shimizu

1 Introduction

2 Nonlinear Optimal Regulator And Hamilton-Jacobi Equation

3 Approximate Solution To Hamilton-Jacobi Equation And Optimal State Feedback Control Law

4 Improvement Of Learning Algorithm Of Neural Network

5 Simulation Results

6 Conclusions

23

$H_{\infty}$ CONTROL BASED ON STATE OBSERVER FOR DESCRIPTOR SYSTEMS

Wei Xing, Q.L. Zhang, W.Q. Liu and Qiyi Wang

1 Introduction

2 Preliminaries

3 Main Results

4 Conclusions

References

Part IV VARIATIONAL INEQUALITY AND EQUILIBRIUM

24 DECOMPOSABLE GENERALIZED VECTOR VARIATIONAL INEQUALITIES

E. Allevi, A. Gnudi and I, V. Konnov

1 Introduction

2 Problem Formulations and Basic Facts

3 Relative Monotonicity Type Properties

4 Existence Results

5 Existence Results in Banach Spaces 
$\begin{array}{lr}\text { References } & 505\end{array}$

25

ON A GEOMETRIC LEMMA AND SET-VALUED VECTOR EQUILIBRIUM PROBLEM

Shui-Hung Hou

1 Introduction $\quad 510$

2 Preliminaries $\quad 511$

3 A Variation of Fan's Geometric Lemma $\quad 511$

4 Set-valued Vector Equilibrium Problem 514

$\begin{array}{ll}\text { References } & 516\end{array}$

26

EQUILIBRIUM PROBLEMS $\quad 519$

$\begin{array}{cl}\text { Giovanna Idone and Antonino Maugeri } & \\ 1 \quad \text { Introduction } & 520\end{array}$

2 A Model of Elastic-Plastic Torsion 521

$\begin{array}{ll}\text { References } & 526\end{array}$

27

GAP FUNCTIONS AND DESCENT METHODS FOR MINTY VARIATIONAL $\quad 529$ INEQUALITY

Giandomenico Mastroeni

1 Introduction $\quad 530$

2 A Gap Function Associated to Minty Variational Inequality 533

3 Exact and Inexact Descent Methods 535

4 Some Applications and Extensions of Minty Variational Inequality 540

5 Concluding Remarks 542

6 Appendix $\quad 542$

$\begin{array}{ll}\text { References } & 545\end{array}$

28

A NEW CLASS OF PROXIMAL ALGORITHMS FOR THE NONLINEAR COM- $\quad 549$

PLEMENTARITY PROBLEM

G.J.P. DA Silva and P.R. Oliveira

1 Introduction $\quad 550$

2 Preliminaries $\quad 552$

3 Existence of Regularized Solutions $\quad 553$

4 Algorithm and Convergence 556

5 Conclusions $\quad 559$

$\begin{array}{ll}\text { References } & 559\end{array}$ 
The 34th Workshop of The International School of Mathematics G. Stampacchia, The International Workshop on Optimization and Control with Applications, was held during July 9-17, 2001 in Ettore Majorana Centre for Scientific Culture, Erice, Sicily, Italy. The Workshop was supported by Italian Ministry of University and Scientific Research, Sicilian Regional Government, The Hong Kong Polytechnic University and The National Cheng Kung University. The Director of The International School of Mathematics G. Stampacchia is Franco Giannessi. The Directors of the Workshop are Liqun Qi and Kok Lay Teo. They jointly organized the Workshop. About 90 scholars from as many as 26 countries and regions attended the Workshop. It consisted of 21 45-minute invited lectures, 45 30-minute contributed talks and 11 15-minute short communications.

This book contains 28 papers emitted from the Workshop. All papers were refereed. A special issue of Journal of Global Optimization containing 6 papers from the Workshop is also published.

The 28 papers are divided into four parts: Part I, Duality and Optimality Conditions, has 6 papers, Part II, Optimization Algorithms, has 9 papers, Part III, Optimal Control, has 8 papers, Part IV, Variational Inequality and Equilibrium Problems, has five papers.

One of the invited lecturers of the Workshop was Professor Elijah (Lucien) Polak, who is a legend in our community. As a survivor of the Holocaust, Lucien has made many significant contributions to optimization and control and their applications. Lucien was close to his 70th birthday during the Workshop. We decided to dedicate this edited volume to him.

We wish to take this opportunity to express our gratitude to Professor Franco Giannessi, the staff of Ettore Majorana Centre for Scientific Culture, and all speakers and participants for their contribution to the success of the Workshop. We would also like to thank Eva Yiu for the clerical work she provided for the workshop. We greatly appreciate the support from the referees of all submissions to this Special Issue for their reviews. 
We are very happy to see that this Workshop has become a new conference series. This Workshop is now regarded as OCA 2001. During August 18-22, 2002, The Second International Conference on Optimization and Control with Applications (OCA2002) was successfully held in Tunxi, China. The Third International Conference on Optimization and Control with Applications (OCA2003) will be held in Chongqing-Chengdu, China, during July 1-7, 2003. Liqun Qi and Kok Lay Teo have continued to be the Directors of OCA 2002 and OCA 2003. We hope that OCA Series will continue to provide a forum for international researchers and practitioners working in optimization, optimal control and their applications to exchange information and ideas on the latest development in these fields.

Liqun Qi, Kok Lay Teo and Xiaoqi Yang The Hong Kong Polytechnic University 
Biographical Sketch of Elijah Polak

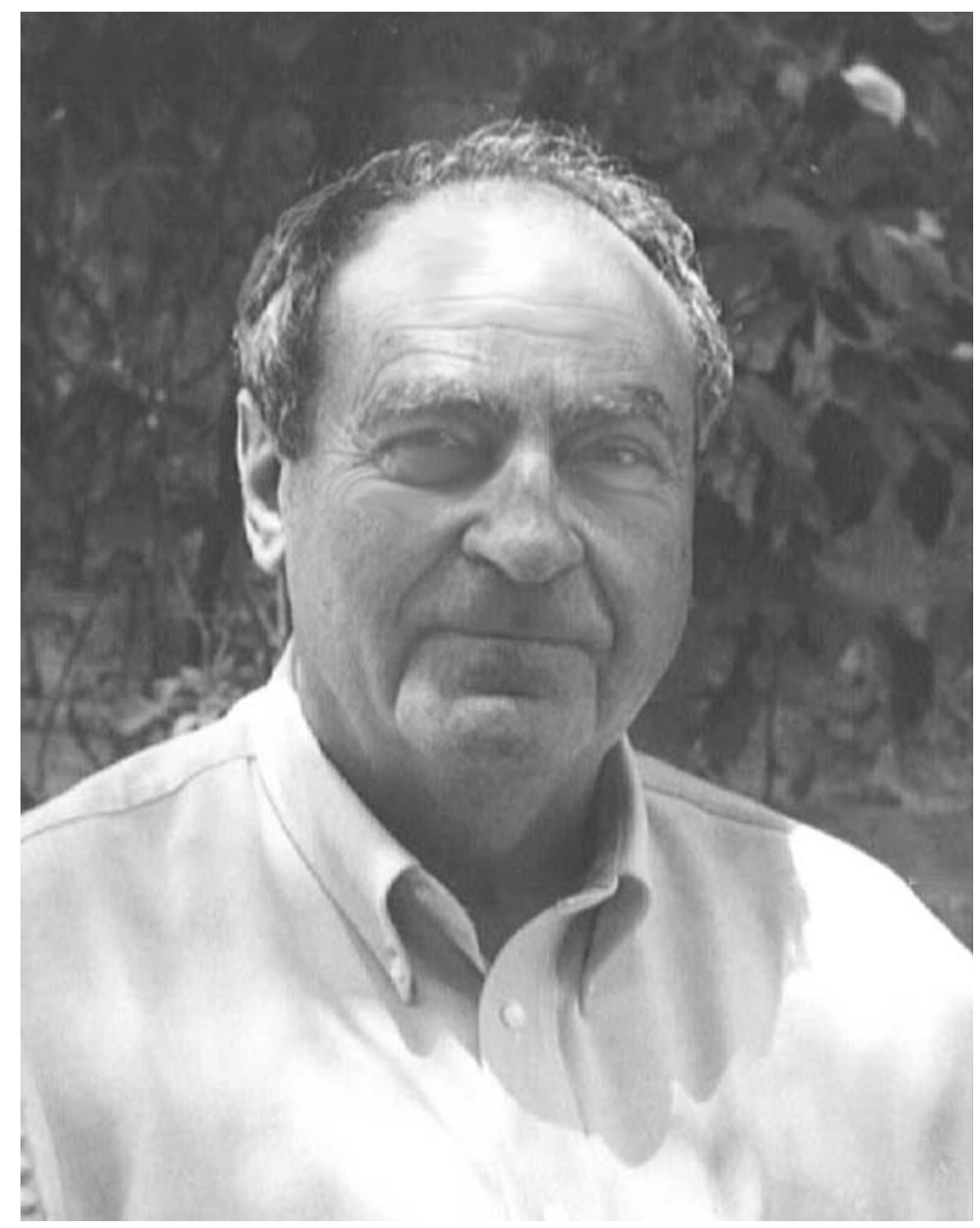

Professor Elijah Polak

Elijah (Lucien) Polak was born August 11, 1931 in Bialystok, Poland. He is a holocaust surviver and a veteran of the death camps at Dachau, Auschwitz, Gros Rosen, and Buchenwald. His father perished in the camps, but his mother survived. After the War, he worked as an apprentice blacksmith in Poland and a clothes salesman in France. In 1949, he and his mother migrated to Australia, where, after an eight year interruption, he resumed his education, while working various part time jobs.

Elijah Polak received the B.S. degree in Electrical Engineering, from the University of Melbourne, Australia, in 1957 and the M.S. and Ph.D. degrees, 
both in Electrical Engineering, from the University of California, Berkeley, in 1959 and 1961, respectively.

In 1961 he married Ginette with whom he had a son and a daughter. At present, they have 5 grandchildren, of which two are beginning to show an interest in mathematics.

From 1957 to 1958 he was employed as an Instrument Engineer by Imperial Chemical Industries, Australia and New Zealand, Ltd., in Melbourne, Australia. He spent the summers of 1959 and 1960 as a Summer Student, with I.B.M. Research Laboratories, San Jose, California, and the Fall Semester of 1964 as a Visiting Assistant Professor, at the Massachusetts Institute of Technology. Since 1961, he has been on the faculty of the University of California, Berkeley, where he is at present Professor Emeritus of Electrical Engineering and Computer Sciences, as well as Professor in the Graduate School.

He was a Guggenheim Fellow in 1968 - 1969, at the Institut Blaise Pascal, in Paris, France, and a United Kingdom Science Research Council Senior Post Doctoral Fellow, at Imperial College, London, England, in 1972, in 1976, in 1979 , in 1982, 1985, 1988, and in 1990.

His research interests lie in the development of optimization algorithms for computer-aided design, with applications to electronic circuit design, control system design, and structural design, as well as algorithms for optimal control and nonsmooth optimization.

He is the author or co-author of over 250 papers as well as of four books: Theory of Mathematical Programming and Optimal Control (with M. Canon and C. Cullum, 1970), Notes of a First Course on Linear Systems (with E. Wong, 1970), Computational Methods in Optimization (1971), and Optimization: Algorithms and Consistent Approximations (1997). In addition, with L. A. Zadeh, he co-edited System Theory (1969), and translated from the Russian Absolute Stability of Regulator Systems, by M. A. Aizerman and F. R. Gantmacher.

He is a Life Fellow of the Institute of Electrical and Electronic Engineers, a member of the Society of Industrial and Applied Mathematics and a member of the Mathematical Programming Society.

$\mathrm{He}$ is an Associate Editor the Journal of Optimization Theory and Applications, and of the Journal of Computational Optimization and Applications. 


\section{A. BOOKS}

1. E. Polak, "Absolute stability of regulator systems", (Translated from Russian) (M. A. Aizerman and F. R. Gantmacher) Holden-Day, 1964.

2. L. A. Zadeh and E. Polak eds., Systems Theory, McGraw-Hill, 521 pages, 1969.

3. Canon, M. D., C. D. Cullum and E. Polak, Theory of Optimal Control and Mathematical Programming, McGraw-Hill Co., New York, 285 pages, 1970.

4. E. Polak and E. Wong, Notes for a First Course on Linear Systems, Van Nostrand Reinhold Co. New York, 169 pages, 1970.

5. E. Polak, Computational Methods in Optimization: A Unified Approach, Academic Press, 329 pages, 1971.

6. E. Polak, Optimization: Algorithms and Consistent Approximations, Springer, New Yort, 800 pages, 1997

\section{B. PAPERS AND REPORTS}

1. E. Polak, "Stability and Graphical Analysis of First-Order Pulse-WidthModulated Sampled-Data Regulator Systems," IRE Trans. on Automatic Control, Vol. AC-6, No. 3, pp. 276-282, 1961.

2. E. Polak, "Minimum Time Control of Second Order Pulse-Width-Modulated Sampled-Data Systems," ASME Trans. Journal of Basic Engineering, Vol. 84, Series D, No. 1, pp. 101-110, 1962.

3. E. Polak and C. A. Desoer, "A Note on Lumped linear Time Invariant Systems," IRE Trans. on Circuit Theory, pp. 282-283, 1962.

4. E. Polak, "Minimal Time Control of a Discrete System with a Nonlinear Plant," IEEE Trans. on Automatic Control, Vol. AC-8, No. 1, pp. 49-56, 1963. 
5. E. Polak, "Exploratory Design of a Hydraulic Position Servo," Instrument Society of Americal Trans., Vol. 2, Issue 3, pp. 207-215, 1963.

6. E. Polak, "On the Equivalence of Discrete Systems in Time-Optimal Control," ASME Trans. Journal of Basic Engineering, Series D, pp. 204-210, 1963.

7. E. Polak, C. A. Desoer, and J. Wing, "Theory of Minimum Time Discrete Regulators," Proc. Second IFAC Congress, Paper No. 406, Basle, 1963.

8. E. Polak, "An Application of Discrete Optimal Control Theory," J. Franklin Inst., Vol. 276, No. 2, pp. 118-127, 1963.

9. H. Kwakernaak and E. Polak, "On the Reduction of the System $\dot{x}=$ $A x+B u, y=c^{\prime} x$ to its Minimal Equivalent," IEEE Trans. on Circuit Theory, Vol. CT-10, No. 4, 1963.

10. E. Polak, "A Note on D-Decomposition Theory," IEEE Trans. on Control, Vol. AC-9, No. 1, January 1964.

11. E. Polak, "Equivalence and Optimal Strategies for some Minimum Fuel Discrete Systems," J. of the Franklin Inst., Vol. 277, No. 2, pp. 150-162, February 1964.

12. E. Polak, "On the Evaluation of Optimal and Non-Optimal Control Strategies," IEEE Trans. on Automatic Control, Vol. AC-9, No. 2, pp. 175$176,1964$.

13. M. D. Canon and E. Polak, "Analog Circuits for Energy and Fuel Optimal Control of Linear Discrete Systems," University of California, Berkeley, Electronics Research Laboratory, Tech. Memo. M-95, August 1964.

14. E. Polak and B. W. Jordan, "Theory of a Class of Discrete Optimal Control Systems," Journal of Electronics and Control, Vol. 17, No. 6, pp. 697-711, 1964.

15. E. Polak and B. W. Jordan, "Optimal Control of Aperiodic Discrete-Time Systems," J. SIAM Control, Vol. 2, pp. 332-346, 1965.

16. E. Polak, "Fundamentals of the Theory of Optimal Control," Mathematical Review, Vol. 29, No. 2, pp. 404-405, 1965. 
17. E. Polak, "An Algorithm for Reducing a Linear Time-Invariant Differential System to State Form," IEEE Trans. on Automatic Control, Vol. AC-11, No. 3, pp. 577-580, 1966.

18. E. Polak, H. Halkin, B. W. Jordan, and J. B. Rosen, "Theory of Optimum Discrete Time Systems," Proc. 3rd IFAC Congress, Paper No. 28B, London, 1966.

19. E. Polak and A. Larsen, Jr., "Some Sufficient Conditions for Continuous Linear Programming Problems," Int'l J. Eng. Science, Vol. 4, No. 5, pp. 583-603, 1966.

20. E. Polak and C. D. Cullum, "Equivalence Relations for the Classification and Solution of Optimal Control Problems," J. SIAM Control, Vol. 4, No. 3, pp. 403-420, 1966.

21. E. Polak, M. D. Canon, and C. D. Cullum, "Constrained Minimization Problems in Finite Dimensional Spaces," J. SIAM Control, Vol. 4, No. 3, pp. 528-547, 1966.

22. E. Polak and J. P. Jacob, "On the Inverse of the Operator $O(\cdot)=A(\cdot)+$ $(\cdot) B, "$ American Mathematical Monthly, Vol. 73, No. 4, Part I, pp. 388-390, April 1966.

23. E. Polak and N. O. Da Cunha, "Constrained Minimization Under Vector Valued-Criteria in Finite Dimensional Spaces," J. Mathematical Analysis \& Applications, Vol. 19, No. 1, pp. 103-124, 1967.

24. E. Polak and N. O. Da Cunha, "Constrained Minimization Under VectorValued Criteria in Linear Topological Spaces," Proc. Conference on Mathematical Theory of Control, Los Angeles, February 1967.

25. E. Polak and K. Y. Wong, "Identification of Linear Discrete Time Systems Using the Instrumental Variable Method," IEEE Trans. on Automatic Control, Vol. AC-12, No. 6, pp. 707-718, 1967.

26. E. Polak, "Necessary Conditions of Optimality in Control and Programming," Proc. AMS Summer Seminar on the Math. of the Decision Sciences, Stanford University, July-August 1967. 
27. E. Polak, "An Algorithm for Computing the Jordan Canonical Form of a Matrix," University of California, Berkeley, Electronics Research Laboratory, Memo. M-223, September 1967.

28. E. Polak and J. P. Jacob, "On a Class of Pursuit-Evasion Problems," IEEE Trans. on Automatic Control, Vol. AC-12, No. 4, pp.752-755, 1967.

29. E. Polak and J. P. Jacob, "On Finite Dimensional Approximations to a Class of Games," J. Mathematical Analysis \& Applications, Vol. 21, No. 2, pp. 287-303, 1968.

30. P. L. Falb and E. Polak, "Conditions for optimality," in L. A. Zadeh and E. Polak, eds., Systems Theory, McGraw-Hill, 1969.

31. E. Polak, "Linear Time Invariant Systems," in L. A. Zadeh and E. Polak, eds., Systems Theory, McGraw-Hill, 1969.

32. E. Polak, "On the Removal of Ill Conditioning Effects in the Computation of Optimal Controls," Automatica, Vol. 5, pp. 607-614, 1969.

33. E. Polak and E. J. Messerli, "On Second Order Necessary Conditions of Optimality," SIAM J. Control, Vol. 7, No. 2, 272-291, 1969.

34. E. Polak, "On primal and Dual Methods for Solving Discrete Optimal Control Problems," Proc. 2nd International Conference on Computing Methods in Optimization Problems, San Remo, Italy, September 9-13, 1968. Published as: Computing Methods in Optimization Problems -2, L. A. Zadeh, L. W. Neustadt and A. V. Balakrishnan, eds., pp. 317-331, Academic Press, 1969.

35. E. Polak, "On the Convergence of Optimization Algorithms," Revue Francaise d'Informatique et de Recherche Operationelle, Serie Rouge, No. 16, pp. 17-34, 1969.

36. E. Polak and G. Ribiere, "Note sur la Convergence de Methodes de Directions Conjuguees," Revue Francaise d'Informatique et de Recherche Operationelle, Serie Rouge, No. 16, 1969.

37. E. Polak and M. Deparis, "An Algorithm for Minimum Energy," IEEE Trans. on Automatic Control, Vol. AC-14, No. 4, pp. 367-378, 1969. 
38. E. Polak, "On the Implementation of Conceptual Algorithms," Proc. Nonlinear Programming Symposium, University of Wisconsin, Madison, Wisconsin, May 4-6, 1970.

39. E. Polak and G. Meyer, "A Decomposition Algorithm for Solving a Class of Optimal Control Problems," J. Mathematical Analysis \& Applications, Vol. 3, No. 1, pp. 118-140, 1970.

40. E. Polak, "On the use of models in the Synthesis of Optimization Algorithms," Differential Games and Related Topics (Proceedings of the International Summer School on Mathematical Models of Action and Reaction, Varenna, Italy, June 15-27, 1970), H. Kuhn and G. Szego eds., North Holland, Amsterdam, pp. 263-279, 1971.

41. E. Polak, H. Mukai and O. Pironneau, "Methods of Centers and of Feasible Directions for the Solution of Optimal Control Problems," Proc. 1971 IEEE Conference on Decision and Control, Miami Beach, Fla., Dec. 15$17,1971$.

42. G. G. L. Meyer and E. Polak, "Abstract Models for the Synthesis of Optimization Algorithms," SIAM J. Control, Vol. 9, No. 4, pp 547, 560, 1971 .

43. O. Pironneau and E. Polak, "On the Rate of Convergence of Certain Methods of Centers," Mathematical Programming, Vol. 2, No. 2, pp. $230-258,1972$.

44. R. Klessig and E. Polak, "Efficient Implementations of the Polak-Ribiere Conjugate Gradient Algorithm," SIAM J. Control, Vol. 10, No. 3, pp. 524-549, 1972 .

45. E. Polak, "On a Class of Numerical Methods with an Adaptive Integration Subprocedure for Optimal Control Problems," Proc. Fourth IFIP Colloquium on Optimization, Santa Monica, Calif. Oct. 19-22, 1971. Published as: Techniques of Optimization, A. V. Balakrishnan, ed., Academic Press, pp. 89-105, 1972.

46. E. Polak, "A Survey of Methods of Feasible Directions for the Solution of Optimal Control Problems," IEEE Transactions on Automatic Control, Vol. AC-17, No. 5, pp. 591-597, 1972. 
47. E. Polak, "A Modified Secant Method for Unconstrained Minimization," Proc. VIII International Symposium on Mathematical Programming, Stanford University, Aug. 27-31, 1973.

48. O. Pironneau and E. Polak, "A Dual Method for Optimal Control Problems with Initial and Final Boundary Constraints," SIAM J. Control, Vol. 11, No. 3, pp. 534-549, 1973.

49. R. Klessig and E. Polak, "An Adaptive Algorithm for Unconstrained Optimization with Applications to Optimal Control," SIAM J. Control, Vol. 11, No. 1, pp. 80-94, 1973.

50. O. Pironneau and E. Polak, "Rate of Convergence of a Class of Methods of Feasible Directions," SIAM J. Numerical Analysis, Vol. 10, No. 1, pp. $161-174,1973$.

51. R. Klessig and E. Polak, "A Method of Feasible Directions Using Function Approximations with Applications to Min Max Problems," J. Math. Analysis and Applications, Vol. 41, No. 3, pp. 583-602, 1973.

52. E. Polak, "On the Use of Optimization Algorithms in the Design of Linear Systems," University of California, Berkeley, Electronics Research Lab. Memo. No. M377, 1973.

53. E. Polak, "A Historical Survey of Computational Methods in Optimal Control," SIAM Review, Vol. 15, No. 2, Part 2, pp. 553-584, 1973.

54. L. J. Williamson and E. Polak, "Convergence Properties of Optimal Control Algorithms," Proc. 1973 IEEE Conference on Decision and Control, Dec. 5-7, 1973.

55. E. Polak, "Survey of Secant Methods for Optimization," Proc. 1973 IEEE Conference on Decision and Control, Dec. 5-7, 1973.

56. E. Polak "A Modified Secant Method for Unconstrained Optimization," Mathematical Programming, Vol. 6, No. 3, pp. 264-280, 1974.

57. E. Polak "A Globally Convergent Secant Method with Applications to Boundary Value Problems," SIAM J. Numerical Analysis, Vol. 11, No. 3, pp. 529-537, 1974. 
58. H. J. Payne, E. Polak, D. C. Collins and S. Meisel, "An Algorithm for Multicriteria Optimization Based on the Sensitivity Function," Proc. 1974 IEEE Conference on Decision and Control, 1974.

59. E. Polak, R. W. H.Sargent and D. J. Sebastian, "On the Convergence of Sequential Minimization Algorithms," J. Optimization Theory and Applications, Vol. 14, No. 4, pp. 439-442, 1974.

60. H. Mukai and E. Polak, "Approximation Techniques in Gradient Projection Algorithms," Proc. IEEE 1974 Allerton Conference on Circuits and Systems, Univ. of Illinois, October, 1974.

61. E. Polak and Teodoru, I., "Newton Derived Methods for Nonlinear Equations and Inequalities," Nonlinear Programming, O. L. Mangasarian, R. R. Meyer and S. M. Robinson eds., Academic Press, N. Y., pp. 255-277, 1975.

62. E. Polak, "Computational Methods in Optimal Control," Proc. Conference on Energy Related Modelling and Data Base Management, Brookhaven National Laboratories, May 12-14, 1975.

63. R. Klessig and E. Polak, "A Survey of Convergence Theorems," Proc. Joint National Meeting, ORSA-TIMS, Las Vegas Nevada, Nov. 17-19, 1975.

64. H. Mukai and E. Polak, "A Quadratically Convergent Primal-Dual Algorithm with Global Convergence Properties for solving optimization with equality constraints," Mathematical Programming, Vol. 9, No. 3, pp. 336-350, 1975.

65. E. Polak, K. S. Pister and D. Ray, "Optimal Design of Framed Structures Subjected to Earthquakes," Proc. Symposium on Optimization and Engineering Design in Conjunction with the 47th national Meeting of ORSA-TIMS, Chicago, Ill. April 30 - May 2, 1975.

66. D. Q. Mayne and E. Polak, "First Order, Strong Variations Algorithms for Optimal Control," J. Optimization Theory and Applications, Vol. 16, No. $3 / 4$, pp. $277-301,1975$.

67. E. Polak and D. Q. Mayne, "First Order, Strong Variations Algorithms for Optimal Control Problems with Terminal Inequality Constraints," $J$. 
Optimization Theory and Applications, Vol. 16, No. 3/4, pp. 303-325, 1975.

68. E. Polak, "On the Approximation of Solutions to Multiple Criteria Decision Making Problems," Proc. XXII International Meeting TIMS, Kyoto, Japan, July, 1975.

69. E. Polak, "On the Global Stabilization of Locally Convergent Algorithms for Optimization and Root Finding," Proc. 6th triannaual IFAC Congress, Boston Mass., Aug. 24-30, 1975.

70. H. J. Payne, E. Polak, D. C. Collins and S. Meisel, "An Algorithm for Multicriteria Optimization Based on the Sensitivity Function," IEEE Transactions on Automatic Control, Vol. AC-20, No. 4, pp. 546-548, 1975.

71. E. Polak and D. Q. Mayne, "An Algorithm for Optimization Problems with Functional Inequality Constraints," IEEE Transactions on Automatic Control, Vol. AC-21, No. 2, 1976.

72. E. Polak and R. Trahan, "An Algorithm for Computer Aided Design of Control Systems," Proc. IEEE Conference on Decision and Control, 1976.

73. E. Polak and A. N. Payne, "On Multicriteria Optimization," Proc. Conference on Directions in Decentralized Control, Many Person Games and Large Scale Systems, Cambridge, Mass, Sept 1-3, 1975. Published as: Directions in Large Scale Systems, Y. C. Ho and K. S. Mitter, eds., Plenum Press, N.Y., pp. 77-94, 1976.

74. L. J. Williamson and E. Polak, "Relaxed Controls and the Convergence of Optimal Control Algorithms," SIAM J. Control, Vol. 14, No. 4, pp. 737-757, 1976.

75. E. Polak, "On the Approximation of Solutions to Multiple Criteria Decision Making Problems," Multiple Criteria Decision Making: Kyoto 1975, M. Zeleny Ed., Springer Verlag, New York, pp. 271-182, 1976.

76. E. Polak, "On the Global Stabilization of Locally Convergent Algorithms for Optimization and Root Finding," Automatica, Vol. 12, pp. 337-342, 1976. 
77. H. Mukai and E. Polak, "On the Implementation of Reduced Gradient Methods," Proc. 7th IFIP Conference on Optimization Techniques, Nice, France, Sept. 8-18, 1975. Published as: Optimization Techniques: Modeling and Optimization in the Service of Man, Jean Cea, ed., Springer Verlag, Berlin, N.Y., Vol. 2, pp. 426-437, 1976.

78. E. Polak, K. S. Pister and D. Ray, "Optimal Design of Framed Structures Subjected to Earthquakes," Engineering Optimization, Vol. 2, pp. 65-71, 1976.

79. D. Q. Mayne and E. Polak, "Feasible Directions Algorithms for Optimization Problems with Equality and Inequality Constraints," Mathematical Programming, Vol. 11, pp. 67-80, 1976.

80. D. Q. Mayne and E. Polak, "A Feasible Directions Algorithm for Optimal Control Problems with Terminal Inequality Constraints," IEEE Transactions on Automatic Control, Vol. AC-22, No. 5, pp. 741-751, 1977.

81. I. Teodoru Gross and E. Polak, "On the Global Stabilization of QuasiNewton Methods," Proc. ORSA/TIMS National Meeting, San Francisco, May 9-11, 1977.

82. D. Ray, K. S. Pister and E. Polak, "Sensitivity Analysis for Hysteretic Dynamical Systems: Theory and Applications," Comp. Meth. in Applied Mechanics and Engineering, Vol. 14, pp. 179-208, 1978.

83. E. Polak, "On a Class of Computer-Aided-Design Problems," Proc. 7th IFAC World Congress, Helsinki, Finland, June 1978.

84. H. Mukai and E. Polak, "On the Use of Approximations in Algorithms for Optimization Problems with Equality and Inequality Constraints," SIAM J. Numerical Analysis, Vol. 1, No. 4, pp. 674-693, 1978.

85. E. Polak and A. Sangiovanni Vincentelli, "An Algorithm for Design Centering, Tolerancing and Tuning," Proc. European Conference on Circuit Theory and Design, Lausanne, Switzerland, Sept. 1978.

86. A. N. Payne and E. Polak, "An Efficient Interactive Optimization Method for Multi-objective Design Problems," Proc. 16th Allerton Conference on 
Communications, Control and Computing, Univ. of Illinois, October 4-6, 1978.

87. H. Mukai and E. Polak, "A Second Order Algorithm for Unconstrained Optimization," J. Optimization Theory and Applications, Vol. 26, No. 4, 1978.

88. H. Mukai and E. Polak, "A second Order Algorithm for the General Nonlinear Programming problem," J. Optimization Theory and Applications, Vol. 26, No. 4, 1978.

89. A. N. Payne and E. Polak, "An Interactive Method for Bi-Objective Decision Making," Proc. Second Lawrence Symposium on Systems and Decision Sciences, Berkeley, Ca. Oct. 1978.

90. E. Polak and A. Sangiovanni Vincentelli, "On Optimization Algorithms for Engineering Design Problems with Distributed Constraints, Tolerances and Tuning," Proc. 1978 Joint Automatic Control Conference, October 18, 1978.

91. M. A. Bhatti, K. S. Pister and E. Polak, "Optimal Design of an Earthquake Isolation System," Earthquake Engineering Research Center, University of California, Berkeley, Report No. UCB/EERC-78/22, October, 1978.

92. T. Glad and E. Polak, "A Multiplier Method with Automatic Limitation of Penalty Growth," Mathematical Programming, Vol. 17, No. 2, pp. 140-156, 1979.

93. E. Polak, D. Q. Mayne and R. Trahan, "An Outer Approximations Algorithm for Computer Aided Design Problems," J. Optimization Theory and Applications, Vol. 28, No. 3, pp. 331-352, 1979.

94. E. Polak and A. Sangiovanni Vincentelli, "Theoretical and Computational Aspects of the Optimal Design Centering, Tolerancing and Tuning Problem," IEEE Trans. on Circuits and Systems, Vol. CAS-26, No. 9, pp. 795-813, 1979 .

95. A. N. Payne and E. Polak, "An Interactive Rectangle Elimination Method for Multi-Objective Decision Making," IEEE Trans. on Automatic Control, Vol. AC-25, No. 3, 1979. 
96. S. Tishyadhigama, E. Polak and R. Klessig, "A Comparative Study of Several General Convergence Conditions for Algorithms Modeled by Point to Set Maps," Mathematical Programming Study 10, pp. 172-190, 1979.

97. E. Polak and D. Q. Mayne, "On the Finite Solution of Nonlinear Inequalities," IEEE Trans. on Automatic Control, Vol. AC-24, No. 3, pp. 443-445, 1979.

98. E. Polak, R. Trahan and D. Q. Mayne, "Combined Phase I - Phase II Methods of Feasible Directions," Mathematical Programming, Vol. 17, No. 1, pp. 32-61, 1979.

99. C. Gonzaga and E. Polak, "On Constraint Dropping Schemes and Optimality Functions for a Class of Outer Approximations Algorithms," SIAM J. Control and Optimization, Vol. 17, No. 4, pp. 477-493, 1979.

100. R. Trahan and E. Polak, "A Derivative Free Algorithm for a Class of Infinitely Constrained Problems," IEEE Trans. on Automatic Control, Vol. AC-25, No. 1, pp. 54-62, 1979.

101. C. Gonzaga, E. Polak and R. Trahan, "An Improved Algorithm for Optimization Problems with Functional Inequality Constraints," IEEE Trans. on Automatic Control, Vol. AC-25, No. 1, pp. 49-54 1979.

102. E. Polak and D. Q. Mayne, "Algorithms for Computer Aided Design of Control Systems by the Method of Inequalities," Proc. 18th IEEE Conference on Decision and Control, Fort Lauderdale, Florida, Dec. 12$14,1979$.

103. E. Polak and S. Tishyadhighama, "New Convergence Theorems for a Class of Feasible Directions Algorithms," Proc. 18th IEEE Conference on Decision and Control, Fort Lauderdale, Florida, Dec. 12-14, 1979.

104. E. Polak and A. Sangiovanni Vincentelli "Theoretical and Computational Aspects of the Optimal Design Centering, Tolerancing and Tuning Problem," Proc. Fourth International Symposium on Mathematical Theory of Networks and Systems, Delft University of Technology, Delft, Holland, July 3-6, 1979. 
105. E. Polak, "On the Nature of Optimization Problems in Engineering Design," Proc. 10th International Symposium on Mathematical Programming, Montreal, Canada, Aug 27-30, 1979.

106. D. Q. Mayne and E. Polak, "A Superlinearly Convergent Algorithm for Constrained Optimization Problems," Electronics Research Laboratory, University of California, Berkeley, Memo. No. UCB/ERL M79/13, Jan. 1979; (presented at the 10th International Symposium on Mathematical Programming, Montreal, Canada, Aug 27-30, 1979. Revised 15/1/1980, Publication No. 78/52, Department of Computing and Control, Imperial College, London.)

107. E. Polak "Algorithms for a Class of Computer Aided Design Problems: a Review," Automatica, Vol. 15, pp. 531-538, 1979.

108. M. A. Bhatti, E. Polak, K. S. Pister, "OPTDYN - A General Purpose Program for Optimization Problems with and without Dynamic Constraints," University of California, Berkeley, Eathquake Engineering Research Center, Report No. UCB/EERC-79/16, July, 1979.

109. M. A. Bhatti, E. Polak, K. S. Pister, "Optimization of Control Devices in Base isolation Systems for Aseismic Design," Proc. International IUTAM Symposium on Structural Control, University of Waterloo, Ontario, Canada, North Holland Pub. Co., Amsterdam, pp. 127-138, 1980.

110. E. Polak, "An Implementable Algorithm for the Optimal Design Centering, Tolerancing and Tuning Problem," Proc. Fourth International Symposium on Computing Methods in Applied Sciences and Engineering, Versailles, France, Dec. 10-14, 1979. Published as: Computing Methods in Applied Science and Engineering, R. Glowinski, J. L. Lions, ed., North Holland, Amsterdam, pp. 499-517, 1980.

111. D. Q. Mayne and E. Polak "An Exact Penalty Function Algorithm for Optimal Control Problems with Control and Terminal Equality Constraints, Part 1," J. Optimization Theory and Applications, Vol. 32 No. 2, pp. 211-246, 1980.

112. D. Q. Mayne and E. Polak "An Exact Penalty Function Algorithm for Optimal Control Problems with Control and Terminal Equality Constraints, 
Part 2," J. Optimization Theory and Applications, Vol. 32 No. 3, pp. 345-363, 1980.

113. E. Polak and A. Tits, "A Globally Convergent Implementable Multiplier Method with Automatic Penalty Limitation," J. Appl. Math. and Optimization, Vol. 6, pp. 335-360, 1980.

114. M. A. Bhatti, K. S. Pister, and E. Polak, "Interactive Optimal Design of Dynamically Loaded Structures," Proc. ASCE conf. on Structural Optimization, Florida, 27-31 Oct. 1980.

115. M. A. Bhatti, K. S. Pister and E. Polak, "An Implementable Algorithm for Computer-Aided Design Problems with or without Dynamic Constraints," Proc. ASME Century 2, International Computer Technology Conference, Aug. 12-15, 1980, San Francisco. Published as: Advances in Computer Technology - 1980, A. Sierig, ed., ASME, New York, Vol. 1., pp. 392-400, Aug. 1980.

116. E. Polak and D. Q. Mayne, "On the Solution of Singular Value Inequalities" Proc. 20th IEEE Conference on Decision and Control, Albuqurque, N.M., Dec. 10-12, 1980.

117. E. Polak and D. Q. Mayne, "Design of Nonlinear Feedback Controllers," Proc. 20th IEEE Conference on Decision and Control, Albuqurque, N.M., Dec. 10-12, 1980.

118. D. Q. Mayne, E. Polak and A. Voreadis, "A Cut Map Algorithm for Design Problems with Tolerances" Proc. 20th IEEE Conference on Decision and Control, Albuqurque, N.M., Dec. 10-12, 1980.

119. M. A. Bhatti, K. S. Pister, and E. Polak, "Interactive Optimal Design of Dynamically Loaded Structures," Proc. 1980 ASCE National Convention, Florida, Dec. 1980.

120. D. Q. Mayne, E. Polak and A. Sangiovanni Vincentelli, "Computer Aided Design via Optimization," Proc. IFAC Workshop on Control Applications of Nonlinear Programming, Denver, Colorado, June 21, 1979. Published as: Control Applications of Nonlinear Programming, H. E. Rauch, ed., Pergamon Press, Oxford and New York, pp. 85-91, 1980. 
121. M. A. Bhatti, K. S. Pister and E. Polak, "Optimization of Control Devices in Base Isolation Systems for Aseismic Design," Structural Control, H. H. E. Leipholz (ed), North Holland Pub. Co. SM Publications, pp. 127-138, 1980.

122. E. Polak, "Optimization-Based Computer-Aided Design of Engineering Systems," FOREFRONT: Research in the College of Engineering, University of California, Berkeley, 1979/80.

123. E. Polak and D. Q. Mayne, "A Robust Secant Method for Optimization Problems with Inequality Constraints," J. Optimization Theory and Applications, Vol. 33, No. 4, pp. 463-467, 1981.

124. E. Polak and D. Q. Mayne, "On the Solution of Singular Value Inequalities over a Continuum of Frequencies" IEEE Transactions on Automatic Control, Vol. AC-26, No. 3, pp. 690-695, 1981.

125. E. Polak and D. Q. Mayne, "Design of Nonlinear Feedback Controllers," IEEE Transactions on Automatic Control, Vol. AC-26, No. 3, pp. 730$733,1981$.

126. W. T. Nye, E. Polak, A. Sangiovanni-Vincentelli and A. Tits, "DELIGHT: an Optimization-Based Computer-Aided-Design System," Proc. IEEE Int. Symp. on Circuits and Systems, Chicago, Ill, April 24-27, 1981.

127. E. Polak and A. Tits, "On globally Stabilized Quasi-Newton Methods for Inequality Constrained Optimization Problems," Proc. 10th IFIP Conference on System Modeling and Optimization, New York, August 31-September 4, 1981.

128. E. Polak, "Optimization-Based Computer-Aided-Design of Control Systems," Proc. Joint Automatic Control Conference, University of Virginia, Charlottesville, Virginia, June 17-19, 1981.

129. E. Polak, "Algorithms for Optimal Design," Proc. NATO Advanced Study Institute, Univ, of Iowa, Iowa City, Ia, May 1980. Published as: Optimization of Distributed Parameter Structures: Vol. 1, E. J. Haug and J. Cea eds., Sijthoff \& Noordhoff, pp. 586-602, 1981. 
130. M. A. Bhatti, T. Essebo, W. Nye, K. S. Pister, E. Polak, A. Sangiovanni Vincentelli and A. Tits, "A Software System for OptimizationBased Computer-Aided Design" Proc. IEEE International Symp. on Circuits and Systems, Houston, Tx, April 28-30, 1980 and also Proc. NATO Advanced Study Institute, Univ. of Iowa, Iowa City, Ia, May 1980. Published as: Optimization of Distributed Parameter Structures: Vol. 1, E. J. Haug and J. Cea eds., Sijthoff \& Noordhoff, pp. 602-620, 1981.

131. E. Polak and Y. Wardi, "A Nondifferentiable Optimization Algorithm for the Design of Control Systems Subject to Singular Value Inequalities over a Frequency Range," Proceedings IFAC/81 World Congress, Kyoto, Japan, August 24-28, 1981.

132. E. Polak, "An Implementable Algorithm for the Design Centering, Tolerancing and Tuning Problem," J. Optimization Theory and Applications, Vol. 35, No. 3, 1981.

133. D. Q. Mayne, E. Polak and A. J. Heunis, "Solving Nonlinear Inequalities in a Finite Number of Iterations," J. Optimization Theory and Applications, Vol. 33, No. 2, pp. 207-221, 1981.

134. M. A. Bhatti, V. Ciampi, K. S. Pister and E. Polak, "OPTNSR an Interactive Software System for Optimal Design of Statically Loaded Structures with Nonlinear Response," University of California, Berkeley, Earthquake Engineering Research Center, Report No. UCB/EERC-81/02, 1981.

135. R. J. Balling, K. S. Pister and E. Polak, "DELIGHT.STRUCT A ComputerAided Design Environment for Structural Engineering," University of California, Berkeley, Earthquake Engineering Research Center Report No. UCB/EERC-81/19, Dec. 1981.

136. R. J. Balling, V. Ciampi, K. S. Pister and E. Polak, "Optimal Design of Seismic-Resistant Planar Steel Frames," University of California, Berkeley, Earthquake Engineering Research Center Report No. UCB/EERC81/20, Dec. 1981.

137. E. Polak, "Interactive Software for Computer-Aided-Design of Control Systems via Optimization," Proc. 20th IEEE Conference of Decision and Control, San Diego, Ca., pp. 408-411, Dec. 16-18, 1981. 
138. M. A. Bhatti, K.S. Pister and E. Polak, "Package for Optimization-Based, Interactive CAD," J. of the Structural Division of the A.S.C.E., Vol. 107, No.ST11, pp. 2271-2284, 1981.

139. E. Polak, K. J. Astrom and D. Q. Mayne, "INTEROPTDYN-SISO: a Tutorial," University of California, Electronics Research Laboratory, Memo UCB/ERL No. M81/99, Dec. 15, 1981.

140. D. Q. Mayne and E. Polak, "Algorithms for the Design of Control Systems Subject to Singular Value Inequalities," Mathematical Programming Studies, Vol. 18, pp. 112-134, 1982.

141. E. Polak and S. Tishyadhigama, "New Convergence Theorems for a Class of Feasible Directions Algorithms," J. Optimization Theory and Applications, Vol. 37, No. 1, pp. 33-44, 1982.

142. M. A. Bhatti, V. Ciampi, K. S. Pister and E. Polak, "An Interactive Software System for Optimal Design of Statically and Dynamically Loaded Structures with Nonlinear Response," Proc. of International Symposium on Optimum Structural Design, Tucson Arizona, October 19-22, 1981. Published as: Optimum Structural Design, R. H. Gallagher et al, eds., John Wiley and Sons, Chichester, England, 1982.

143. D. Q. Mayne, E. Polak and A. Voreadis, "A Cut Map Algorithm for Design Problems with Tolerances," IEEE Trans. on Circuits and Systems, Vol. CAS-29 No. 1, pp. 35-46, 1982.

144. D. Q. Mayne, E. Polak and A. Sangiovanni Vincentelli, "Computer Aided Design via Optimization: a Review," Automatica, Vol. 18, No. 2, pp. $147-154,1982$.

145. D. Q. Mayne and E. Polak, "A Superlinearly Convergent Algorithm for Constrained Optimization Problems," Mathematical Programming Study 16, pp. 45-61, 1982.

146. E. Polak and Y. Wardi, "A Nondifferentiable Optimization Algorithm for the Design of Control Systems Subject to Singular Value Inequalities over a Frequency Range," Automatica, Vol. 18, No. 3, pp. 267-283, 1982. 
147. D. Q. Mayne and E. Polak, "Algorithms for the Design of Control Systems Subject to Singular Value Inequalities," Mathematical Programming Study 18, Algorithms and Theory in Filtering and Control, D. C. Sorensen and R. J.-B. Wets, ed., North Holland, New York, pp. 112-135, 1982.

148. E. Polak and A. Tits, "A Recursive Quadratic Programming Algorithm for Semi-Infinite Optimization Problems," J. Appl. Math. and Optimization, Vol. 8, pp. 325-349, 1982.

149. Balling, R. J., Ciampi, V., Pister K. S. Polak, E, Sangiovanni Vincentelli, A., Tits, A., "DELIGHT.STRUCTURE: An Interactive Software System for Optimization-Based Computer-Aided Design of Dynamically Loaded Structures with Nonlinear Response," Proc. ASCE Convention, Las Vegas, 1982.

150. Balling, R. J., Ciampi, V., Pister K. S. Polak, E., "Optimal Design of Structures Subjected to Earthquake Loading," Proc. ASCE Convention, Las Vegas, 1982.

151. E. Polak, P. Siegel and T. Wuu, W. T. Nye and D. Q. Mayne, "DELIGHTMIMO an Interactive, Optimization based Multivariable Control System Design Package," IEEE Control Systems Magazine, Vol. 2, No. 4, pp. $9-14,1982$.

152. D. Q. Mayne and E. Polak, "A Quadratically Convergent Algorithm for Solving Infinite Dimensional Inequalities," J. of Appl. Math. and Optimization, Vol. 9., pp. 25-40, 1982.

153. E. Polak, D.Q. Mayne and Y. Wardi, "On the Extension of Constrained Optimization Algorithms from Differentiable to Nondifferentiable Problems," SIAM J. Control and Optimization, Vol. 21, No. 2, pp. 179-204, 1983.

154. Y.Y. Wardi and E. Polak, "A Nondifferentiable Optimization Algorithm for Structural Problems with Eigenvalue Constraints," Journal of Structural Mechanics, Vol. 11, No. 4, 1983.

155. E. Polak and D. Q. Mayne, "On Three Approaches to the Construction of Nondifferentiable Optimization Algorithms," Proc. 11th IFIP Conference 
xxxiv

on System Modelling and Optimization, Copenhagen, Denmark, July 2529, 1983.

156. Polak, E. and Stimler, D. M. "Optimization-Based Design of SISO Control Systems with Uncertain Plant: Problem Formulation," University of California, Berkeley, Electronics Research Laboratory Memo No. UCB/ERL M83/16, 1983.

157. Polak, E. and Stimler, D. M. "Optimization-based Design of SISO Control Systems with Uncertain Plant," Proc. IFAC Symp. on Applications of Nonlinear Programming to Optimization and Control, San Francisco, June 20-21, 1983.

158. Polak, E. and Stimler, D. M. "Complexity Reduction in OptimizationBased Design of Control Systems with Uncertain Plant," Proc. American Automatic Control Conference, San Francisco, June 22-24, 1983.

159. E. Polak, "Semi-Infinite Optimization in Engineering Design," Lecture Notes in Economics and Mathematical Systems, Vol. 215: Semi-Infinite Programming and Applications, A. V. Fiacco and K. O. Kortanek, eds., Springer-Verlag, Berlin, New York, Tokyo, 1983.

160. E. Polak and Y. Y. Wardi, "A Study of Minimizing Sequences," Proc. IEEE Conference on Decision and Control, San Antonio, Tx., pp. 923928, Dec. 1983.

161. Polak and D. Q. Mayne, "Algorithm Models for Nondifferentiable Optimization," Proc. IEEE Conference on Decision and Control, San Antonio, Tx., pp. 934-939, Dec. 1983.

162. R. J. Balling, K. S. Pister and E. Polak, "DELIGHT.STRUCT A ComputerAided Design Environment for Structural Engineering," Computer Methods in Applied Mechanics and Engineering, 38, pp. 237-251, 1983.

163. E. Polak, "A Modified Nyquist Stability Criterion for Use in ComputerAided Design," IEEE Trans. on Automatic Control, Vol. AC-29, No. 1, pp. 91-93, 1984.

164. E. Polak and D.M. Stimler, "On the Design of Linear Control Systems with Plant Uncertainty via Nondifferentiable Optimization," Proc. IX. Triennial IFAC World Congress, Budapest, July 2-6, 1984. 
165. D. Q. Mayne and E. Polak, "Outer Approximations Algorithm for Nondifferentiable Optimization Problems," J. Optimization Theory and Applications, Vol. 42, No. 1, pp. 19-30, 1984.

166. E. Polak, "Notes on the Mathematical Foundations of Nondifferentiable Optimization in Engineering Design," University of California, Electronics Research Laboratory, Memo UCB/ERL M84/15, 2 Feb. 1984.

167. E. Polak and D. Q. Mayne, "Theoretical and Software Aspects of Optimization Based Control System Design," Proceedings of the Sixth International Conference Analysis and Optimization of Systems, Nice, France, June 19-22, 1984.

168. E. Polak, "A Perspective on the Use of Semi-Infinite Optimization in Control System Design," Proc. 1984 Automatic Control Conference, San Diego, June 1984.

169. D. Q. Mayne and E. Polak, "Nondifferentiable Optimization via Adaptive Smoothing," J. Optimization Theory and Applications, Vol. 43, No. 4, pp. 601-614, 1984.

170. E. Polak and Y. Y. Wardi, "A Study of Minimizing Sequences," SIAM J. Control and Optimization, Vol. 22, No. 4, pp. 599-609, 1984.

171. M. A. Bhatti, V. Ciampi, K. S. Pister and E. Polak, "An Interactive Software System for Optimal Design with Nonlinear Response," New Directions in Optimum Structural Design, E. Atrek, R. H. Gallagher, K. M. Ragsdell and O. C. Zienkewicz eds., pp. 633-663, John Wiley and Sons, New York, N.Y. 1984,

172. E. Polak, D. Q. Mayne and D. M. Stimler, "Control System Design via Semi-Infinite Optimization," Proceedings of the IEEE, pp. 1777-1795, December 1984.

173. E. Polak, S. Salcudean and D. Q. Mayne, "A Rationale for the Sequential Optimal Redesign of Control Systems," Proc. 1985 ISCAS, pp. 835-838, Kyoto, Japan, June 1985.

174. E. Polak, S. Salcudean and D. Q. Mayne, "A Sequential Optimal Redesign Procedure for Linear Feedback Systems," University of California, 
Berkeley, Electronics Research laboratory Memo No. UCB/ERL M85/15, Feb.28, 1985.

175. D. Q. Mayne and E. Polak "Algorithms for Optimization Problems with Exclusion Constraints," Proc. 1985 IEEE Conference on Decision and Control, Fort Lauderdale, Florida, Dec. 1985.

176. E. Polak and D. M. Stimler, "On the Efficient Formulation of the Optimal Worst Case Control System Design Problem," University of California, Electronics Research Laboratory Memo No. UCB/ERL M85/71, 21 August 1985 .

177. E. Polak and D. Q. Mayne, "Algorithm Models for Nondifferentiable Optimization," SIAM J. Control and Optimization, Vol. 23, No. 3, 1985.

178. T. L. Wuu, R. G. Becker and E. Polak, "A Diagonalization Technique for the Computation of Sensitivity Functions of Linear Time Invariant Systems," IEEE Trans. on Automatic Control, Vol. AC-31 No. 12, pp. 1141-1143, 1986.

179. E. Polak and D. M. Stimler, "Majorization: a Computational Complexity Reduction Technique in Control System Design," Proceedings of the Seventh International Conference Analysis and Optimization of Systems, Antibes, France, June, 1986.

180. D. M. Stimler and E. Polak, "Nondifferentiable Optimization in Worst Case Control Systems Design: a Computational Example," Proc. IEEE Control Systems Society 3rd Symposium on CACSD, Arlington, Va., September 24-26, 1986.

181. D. Q. Mayne and E. Polak "Algorithms for Optimization Problems with Exclusion Constraints," J. Optimization Theory and Applications, Vol. 51, No. 3, pp. 453-474, 1986

182. E. Polak, "A Perspective on Control System Design by Means of SemiInfinite Optimization Algorithms," Proc. IFIP Working Conference on Optimization Techniques, Santiago, Chile, Aug. 1984. Springer Verlag. 1987 
183. E. Polak and D. Q. Mayne, "Design of Multivariable Control Systems via Semi-Infinite Optimization," Systems and Control Encyclopaedia, M. G. Singh, editor, Pergamon Press, N.Y. 1987.

184. D. Q. Mayne and E. Polak "An Exact Penalty Function Algorithm for Control Problems with State and Control Constraints," IEEE Trans. on Control, Vol. AC-32, No. 5, pp. 380-388, 1987.

185. E. Polak, S. Salcudean and D. Q. Mayne, "Adaptive Control of ARMA Plants Using Worst Case Design by Semi-Infinite Optimization, IEEE Trans. on Automatic Control, Vol. AC-32, No. 5, pp. 388-397, 1987.

186. E. Polak, "On the Mathematical Foundations of Nondifferentiable Optimization in Engineering Design," SIAM Review, Vol.29, No.1 pp. 21-91, March 1987.

187. E. Polak, T. E. Baker, T-L. Wuu and Y-P. Harn "Optimization-Based Design of Control Systems for Flexible Structures," Proc. 4-th Annual NASA SCOLE Workshop, Colorado Springs, December 1987.

188. S. Daijavad, E. Polak, and R-S Tsay, "A Combined Deterministic and Random Optimization Algorithm for the Placement of Macro-Cells," Proc. MCNC International Workshop on Placement and Routing, Research Triangle Park, NC, May 10-13, 1988.

189. E. Polak and S. E. Salcudean, "Algorithms for Optimal Feedback Design," Proc. International Symposium on the Mathematical Theory of Networks and Systems (MTNS/87), Phoenix, Arizona, June 15-19, 1987: .br C. I. Byrnes, C. F. Martin, and R. E. Saeks eds., Linear Circuits, Systems and Signal Processing: Theory and Applications, Elsevier Science Pub. B.V. (North Holland), 1988.

190. T. E. Baker and E. Polak, "Computational Experiments in the Optimal Slewing of Flexible Structures," Proc. Second NASA/Air Force Symposium on Recent Advances in Multidisciplinary Analysis and Optimization, Hampton, Va., Sept. 28-30, 1988.

191. E. Polak, "Minimax Algorithms for Structural Optimization," Proc. IUTAM Symposium on Structural Optimization, Melbourne, Australia, Feb. $9-13,1988$. 
192. E. Polak and E. J. Wiest, "Domain Rescaling Techniques for the Solution of Affinely Parametrized Nondifferentiable Optimal Design Problems," Proc. 27th IEEE Conference on Decision and Control, Austin, Tx., Dec. 7-9 1988. Dec. 1988.

193. E. Polak and D. M. Stimler, "Majorization: a Computational Complexity Reduction Technique in Control System Design," IEEE Trans. on Automatic Control, Vol. 33, No.11, pp 1010-1022, 1988.

194. E. Polak and S. E. Salcudean, "On The Design of Linear Multivariable Feedback Systems via Constrained Nondifferentiable Optimization in Hsupinf Spaces," IEEE Trans on Automatic Control, Vol. 34, No.3, pp 268-276, 1989.

195. E. Polak and S. Wuu, "On the Design of Stabilizing Compensators via Semi-Infinite Optimization," EEE Trans. on Control, Vol. 34, No.2, pp 196-200, 1989.

196. E. Polak, "Nonsmooth Optimization Algorithms for the Design of Controlled Flexible Structures," Proc. AMS-SIAM-IMS Joint Summer Research Conf. on Dynamics and Control of Multibody Systems , July 30- August 5, 1988, Bowdoin College, Brunswick, Maine. Contemporary Mathematics Vol. 97, pp 337-371, J. E. Marsden, P. S. Krishnaprasad, and J. C. Simo eds., American Math Soc., Providence RI, 1989.

197. E. Polak, "Basics of Minimax Algorithms," Proc. Fourth Course of the International School of Mathematics on Nonsmooth Optimization and Related Topics Erice, Italy, June 19 - July 8 1988. Published as (pp 343367): Nonsmooth Optimization and Related Topics, F. H. Clarke, V. F. Dem'yanov and F. Giannessi eds., Plenum Press, New York, 1989.

198. L. He and E. Polak, "Effective Discretization Strategies in Optimal Design," Proceedings 28th IEEE Conference on Decision and Control, Tampa, FL., December 12-14, 1989.

199. Y-P. Harn and E. Polak, "On the Design of Finite Dimensional Controllers for Infinite Dimensional Feedback-Systems via Semi-Infinite Optimization," Proc. 27th IEEE Conference on Dec. and Contr., Austin, Tx., Dec. 7-9 1988. IEEE Trans. on Automatic Control, Vol. 35, No. 10, pp. 1135-1140, 1990 
200. J. E. Higgins and E. Polak, "Minimizing Pseudo-Convex Functions on Convex Compact Sets," J. Optimization Theory and Applications, Vol.65, No.1, pp 1-28, 1990.

201. E. Polak and E. J. Wiest, "A Variable Metric Technique for the Solution of Affinely Parametrized Nondifferentiable Optimal Design Problems," J. Optimization Theory and Applications, Vol. 66, No. 3, pp 391-414, 1990.

202. L. He and E. Polak, "An Optimal Diagonalization Strategy for the Solution of a Class of Optimal design Problems," IEEE, Trans. on Automatic Control, Vol. 35, No.3, pp 258-267, 1990.

203. T. E. Baker and E. Polak, "An Algorithm for Optimal Slewing of Flexible Structures," University of California, Electronics Research Laboratory, Memo UCB/ERL M89/37, 11 April 1989, Revised, 4 June 1990.

204. E. Polak, T. Yang, and D. Q. Mayne, "A Method of Centers Based on Barrier Functions for Solving Optimal Control Problems with Continuum State and Control Constraints," Proc. 29-th IEEE Conf. on Decision and Control, Honolulu, Hawaii, Dec. 5-7, 1990.

205. L. He and E. Polak, "Effective Diagonalization Strategies for the Solution of a Class of Optimal Design Problems," IEEE Trans. on Automatic Control, Vol. 35, No.3, pp 258-267, 1990.

206. D. Q. Mayne, H. Michalska and E. Polak, "An Efficient Outer Approximations Algorithm for Solving Infinite Sets of Inequalities," Proc. 29-th IEEE Conf. on Dec. and Control, Honolulu, Hawaii, Dec. 5-7, 1990.

207. Y-P. Harn and E. Polak, "On the Design of Finite Dimensional Controllers for Infinite Dimensional Feedback-Systems via Semi-Infinite Optimization," IEEE Trans. on Automatic Control, Vol. 35, No. 10, pp. 1135-1140, 1990.

208. E. Polak, D. Q. Mayne and J. Higgins, "A Superlinearly Convergent Algorithm for Min-Max Problems," J. Optimization Theory and Applications Vol. 69, No.3, pp 407-439, 1991.

209. Y-P. Harn and E. Polak, "Proportional-Plus-Multiintegral Stabilizing Compensators for a Class of MIMO Feedback Systems with Infinite- 
Dimensional Plants," IEEE Trans. on Automatic Control, Vol. 36, No. 2, pp. 207-213, 1991.

210. E. Polak and L. He, "A Unified Phase I Phase II Method of Feasible Directions for Semi-infinite Optimization," J. Optimization Theory and Applications, Vol. 69, No.1, pp 83-107, 1991.

211. J. Higgins and E. Polak, "An $\epsilon$-active Barrier Function Method for Solving Minimax Problems," J. Applied Mathematics and Optimization, Vol. 23, pp 275-297, 1991.

212. E. J. Wiest and E. Polak, "On the Rate of Convergence of Two Minimax Algorithms," J. Optimization Theory and Applications Vol. 71 No.1, pp $1-30,1991$.

213. E. Polak and L. He, "Finite-Termination Schemes for Solving Semi-Infinite Satisfycing Problems," J. Optimization Theory and Applications, Vol. 70, No. 3, pp 429-466, 1991.

214. L. He and E. Polak, "Multistart Method with Estimation Scheme for Global Satisfycing Problems," Proc. European Control Conference, Grenoble, July 2-5, 1991.

215. C. Kirjner Neto and E. Polak, "A Secant Method Based on Cubic Interpolation for Solving One Dimensional Optimization Problems," University of California, Berkeley, Electronics Research Laboratory Memo No. UCB/ERL M91/91, 15 October 1991.

216. E. Polak, J. Higgins and D. Q. Mayne, "A Barrier Function Method for Minimax Problems," Mathematical Programming, Vol. 54, No.2, pp. 155-176, 1992.

217. E. Polak, D. Q. Mayne, and J. Higgins, "On the Extension of Newton's Method to Semi-Infinite Minimax Problems," SIAM J. Control and Optimization, Vol. 30, No.2, pp. 376-389, 1992.

218. E. Polak and L. He, "Rate Preserving Discretization Strategies for Semiinfinite Programming and Optimal Control," SIAM J. Control and Optimization, Vol. 30, No. 3, pp 548-572, 1992 
219. E. J. Wiest and E. Polak, "A Generalized Quadratic Programming-Based Phase I Phase II Method for Inequality Constrained Optimization," J. Appl. Mathematics and Optimization, Vol. 26, pp 223-252, 1992.

220. T. H. Yang and E. Polak, "Moving Horizon Control of Nonlinear Systems with Input Saturation, Disturbances, and Plant Uncertainty," International Journal on Control Vol. 58. No.4, pp. 875-903, 1993.

221. E. Polak and T. H. Yang, "Moving Horizon Control of Linear Systems with Input Saturation, and Plant Uncertainty, Part 2. Disturbance Rejection and Tracking," International Journal on Control, Vol. 68, No. 3, pp. 639-663, 1993.

222. E. Polak and T. H. Yang, "Moving Horizon Control of Linear Systems with Input Saturation, and Plant Uncertainty, Part 1. Robustness," International Journal on Control, Vol. 68, No. 3, pp. 613-638, 1993.

223. E. Polak, "On the Use of Consistent Approximations in the Solution of Semi-Infinite Optimization and Optimal Control Problems," Mathematical Programming, Series B, Vol. 62, No.2, pp 385-414, 1993.

224. L. He and E. Polak, "Multistart Method with Estimation Scheme for Global Satisfycing Problems," J. Global Optimization, No.3, pp 139-156, 1993.

225. E. Polak, T. Yang, and D. Q. Mayne, "A Method of Centers Based on Barrier Functions for Solving Optimal Control Problems with Continuum State and Control Constraints," Siam J. Control and Optimization, Vol.31, pp 159-179, 1993.

226. D. Q. Mayne and E. Polak, "Optimization Based Design and Control," plenary address, Proc. IFAC Congress, July 1993, Sydney, Australia.

227. T. E. Baker and E. Polak, "On the Optimal Control of Systems Described by Evolution Equations," SIAM J. Control and Optimization, Vol. 32, No. 1, pp 224-260, 1994

228. E. Polak, G. Meeker, K. Yamada and N. Kurata, "Evaluation of an Active Variable-Damping-Structure," Earthquake Engineering and Structural Dynamics, Vol. 23, pp 1259-1274, 1994. 
229. D. Q. Mayne, H. Michalska and E. Polak, "An Efficient Algorithm for Solving Semi-Infinite Inequality Problems with Box Constraints," J. Applied Mathematics and Optimization, Vol. 30 No.2, pp. 135-157, 1994.

230. C. Kirjner-Neto, E. Polak, and A. Der Kiureghian, "Algorithms for ReliabilityBased Optimal Design," Proc. IFIP Working Group 7.5 Working Conference on Reliability and Optimization of Structural Systems, Assisi (Perugia), Sept 7-9, 1994.

231. C. Kirjner Neto and E. Polak, "On the Use of Consistent Approximations for the Optimal Design of Beams," SIAM Journal on Control and Optimization, Vol. 34, No. 6, pp. 1891-1913, 1996.

232. A. Schwartz and E. Polak, "Consistent Approximations for Optimal Control Problems Based on Runge-Kutta Integration," SIAM Journal on Control and Optimization, Vol. 34., No.4, pp. 1235-69, 1996.

233. A. Schwartz and E. Polak, "A Family of Projected Descent Methods for Optimization Problems with Simple Bounds," J. Optimization Theory and Applications, Vol. 92, No.1, pp.1-32, 1997.

234. E. Polak, C. Kirjner-Neto, and A. Der Kiureghian, "Structural optimization with reliability constraints," Proc. 7th IFIP WG 7.5 Conference on Reliability and Optimization of Structural Systems Boulder, Colorado, USA. 2-4 April, 1996. Published as Reliability and Optimization of Structural Systems, D. M. Frangopol, R. Corotis, and R. Rackwitz eds, Pergamon, 1997.

235. I. S. Khalil-Bustany, C. J. Diederich, E. Polak, and A. W. Dutton, "A Three Dimensional Minimax Optimization-Based Inverse Treatment Planning Approach for Interstitial Thermal Therapy Using Multi-Element Applicators," Proc. 16th Annual Meeting North American Hyperthermia Soc., Rhode Island, 1997.

236. I. S. Khalil, C. J. Dietrich, E. Polak, and A. W. Dutton, "Three Dimensional Minimax Optimization Based Inverse Treatment Planning for Interstitial Thermal Therapy Using Multi-Element Applicators," Proc. North American Hyperthermia Society - 16th Annual Meeting, Providence RI, April 1997. 
237. E. Polak and L. Qi, "A Globally and Superlinearly Convergent Scheme for Minimizing a Normal Merit Function", AMR 96/17, Applied Mathematics Report, University of New South Wales, 1996, and SIAM J. on Optimization, Vol. 36, No. 3, p.1005-19, 1998.

238. C. Kirjner and E. Polak, "On the Conversion of Optimization Problems with MaxMin Constraints to Standard Optimization Problems," SIAM J. Optimization, Vol. 8, No. 4, pp 887-915, 1998.

239. C. Kirjner-Neto, E. Polak and A. Der Kiureghian, "An Outer Approximations Approach to Reliability-Based Optimal Design of Structures," J. Optimization Theory and Applications, Vol. 98, No.1, pp. 1-17, July 1998.

240. I. S. Khalil-Bustany, C. J. Diederich, C. Kirjner-Neto, and E. Polak, "A Minimax Optimization-Based Inverse Treatment Planning Approach for Interstitial Thermal Therapy," International Journal of Hyperthermia Vol. 14, No. 4 pp 331-346, 1998.

241. E. Polak and L. Qi, "Some Optimality Conditions for Minimax Problems and Nonlinear Programs," Applied Mathematics Report AMR 98/4, University of New South Wales, 1998.

242. N. di Cesare, O. Pironneau, E. Polak. "Consistent Approximations for an Optimal Design Problem," LAN-UPMC report 98005, Universite Pierre et Marie Curie, Paris, France, January 1998. Paris, Jussieu, March 1998.

243. A. der Kiureghian and E. Polak, "Reliability-Based Optimal Structural Design: a Decoupled Approach," Proc. 8th IFIP WG 7.5 Conference on Reliability and Optimization of Structural Systems, Krakow, Poland, 11-13 May, 1998.

244. L. Davis, R. Evans, and E. Polak, "Maximum Likelyhood Estimation of Positive Definite hermitian Toeplitz Matrices Using Outer Approximations," Proc. 9th IEEE Signal Processing Workshop on Statistical Signal and Array Processing, Portland, Oregon, September 14-16, pp. 49-52, 1998.

245. J. S. Maltz, E. Polak, and T. F. Budinger, "Multistart Optimisation Algorithm for Joint Spatial and Kinetic Parameter Estimation in Dynamic 
ECT," 1998 IEEE Nuclear Science Symposium and Medical Imaging Conference Record, Toronto, Canada, November 9-14, 1998.

246. E. Polak, L. Qi, and D. Sun, "First-Order Algorithms for Generalized Finite and Semi-Infinite Min-Max Problems," Computational Optimization and Applications, Vol.13, No.1-3, Kluwer Academic Publishers, p.137-61, 1999.

247. E. Polak, R. J-B. Wets, and A. der Kiureghian, "On an Approach to Optimization Problems with a Probabilistic Cost and or Constraints," in Nonlinear Optimization and Related Topics, pp. 299-316, G.Di Pillo and F.Giannessi, Editors, Kluwer Academic Publishers B.V., 2000.

248. Geraldine Lemarchand, Olivier Pironneau, and Elijah Polak, "A Mesh Refinement Method for Optimization with DDM," Proc. 13th International Conference on Domain Decomposition Methods, Champfleuri, Lyons, France, October 9-12, 2000.

249. J. Royset, A. der Kiureghian, and E. Polak, "Reliability-based Optimal Design with Probabilistic Cost and Constraint," in Proceeding of the 9th IFIP Working Conference on Optimization and Reliability of Structrual Systems, Ann Arbor, Michigan, Sep 2000. A.S. Nowak and M.M. Szerszen (Eds.), Univ. of Michigan, Ann Arbor, pp. 209-216, 2000.

250. E. Polak, "First-Order Algorithms for Optimization Problems With a Maximum Eigenvalue/Singular Value Cost and or Constraints," M. A. Goberna and M. A. Lopez, eds, Semi-Infinite Programming: Recent Advances, Kluwer Academic Publishers, pp. 197-220, 2001.

251. J. Royset, A. der Kiureghian, and E. Polak, "Reliability-based Optimal Structural Design by the Decoupling Approach," Journal of Reliability Engineering and System Safety, Elsevier Science, Vol. 73, No. 3, p. 213-221, 2001.

252. J. Royset, A. der Kiureghian, and E. Polak, "Reliability-based Optimal Design of Series Structural Systems," Journal of Engineering Mechanics, 127, 6, p. 607-614, 2001. 
253. E. Polak, L. Qi and D. Sun, "Second-Order Algorithms for Generalized Finite and Semi-Infinite Min-Max Problems," SIAM Journal on Optimization, Vol.11, 218 (no.4), p.937-61, 2001.

254. E. Polak and M. Wetter, "Generalized Pattern Search Algorithms with Adaptive Precision Function Evaluations," University of California ERL Memo No UCB/ERL M01/30, 7 September 2001.

255. E. Polak, "Smoothing Techniques for the Solution of Finite and SemiInfinite Min-Max-Min Problems," High Performance Algorithms and Software for Nonlinear Optimization, G. Di Pillo and A. Murli, Editors, Kluwer Academic Publishers B.V., 2002

256. O. Pironneau and E. Polak, "On a Consistent Approximations Approach to Optimal Control Problems with Two Numerical Precision Parameters," High Performance Algorithms and Software for Nonlinear Optimization, G. Di Pillo and A. Murli, Editors, Kluwer Academic Publishers B.V., 2002 .

257. O. Pironneau and E. Polak, "Consistent Approximations and Approximate Functions and Gradients in Optimal Control," J. SIAM Control and Optimization, Vol. 41, pp. 487-510, 2002.

258. J.O. Royset, E. Polak and A. Der Kiureghian, "FORM Analysis USIng Consistent Approximations," Proceedings of the 15th ASCE Engineering Mechanics Conference, New York, NY, 2002.

259. E. Polak and J.O. Royset, "Algorithms with Adaptive Smoothing for Finite Min-Max Problems," J. Optimization Theory and Applications, submitted 2002 .

260. E. Polak and J.O. Royset, "Algorithms for Finite and Semi-Infinite MinMax-Min Problems Using Adaptive Smoothing Techniques," J. Optimization Theory and Applications, submitted 2002.

261. J.O. Royset, E. Polak and A. Der Kiureghian, "Adaptive Approximations and Exact Penalization for the Solution of Generalized Semi-Infinite MinMax Problems," to appear in SIAM J. Optimization, 
xlvi OPTIMIZATION AND CONTROL WITH APPLICATIONS

262. A. Brockwell, E. Polak, R. Evans, and D. Ralph, "Dual-Sampling-Rate Moving Horizon Control of a Class of Linear Systems with Input Saturation and Plant Uncertainty," Carnegie Mellon, Dept. of Statistics Report No. 733, 11/00, 2000. To appear in J. Optimization Theory and Applications. 
DUALITY AND OPTIMALITY CONDITIONS 